\title{
Towards Sustainable Urban Transportation in Ghana: Exploring Adults' Intention to Adopt Cycling to Work Using Theory of Planned Behaviour and Structural Equation Modelling
}

\author{
Ransford A. Acheampong ${ }^{1}$
}

Received: 17 December 2015 / Accepted: 11 August 2017 / Published online: 17 August 2017

(C) The Author(s) 2017. This article is an open access publication

\begin{abstract}
Cycling is considered an environmentallyfriendly mode of transport that offers many personal benefits including health, affordability and flexibility of travel. To encourage more people to cycle, especially in contexts where cycle ownership and ridership is considerably low, requires understanding the underlying motivations and barriers to cycling. This study models the behavioural influences of individuals' $(\mathrm{N}=348)$ intended adoption of cycling to work in the Kumasi metropolis in Ghana, West Africa. It deploys the theory of planned behaviour (TPB) to explore the extent to which socio-psychological constructs namely; Attitude, perceived behavioural (PBC) and subjective norm (SN) influence intended adoption of cycling as work travel mode. The influence of participants' perception of their physical environment as well as their personal characteristics, cycling history and bicycle ownership are also examined. Results of an SEM analysis showed that among the TPB constructs, PBC (i.e. perception of self-confidence, personal control and ease of cycling) had the strongest positive and direct effect on participants' intention to cycle to work. Negative associations were found between attitude and SN and SN and PBC, suggesting that belief about the prestige of cycling relative to other modes, and approval of society and significant others of cycling, influenced perception of control and confidence as well as attitude with respect to cycling. Also, participants' perception of their environment including traffic-lights, traffic volume and congestion, as well as bicycle ownership and frequency of use, increased intended adoption of cycling. Finally, being female decreased the likelihood of intended
\end{abstract}

Ransford A. Acheampong

raa49@cam.ac.uk

1 Department of Land Economy, University of Cambridge, 19 Silver Street, Cambridge CB3 9EP, UK cycling adoption. Cycling promotion interventions could be anchored on people's already strong perceived control and confidence to cycle while addressing negative perceptions and attitudes towards cycling as a mainstream transport mode.

Keywords Cycling - Active transport - Theory of planned behaviour $\cdot$ Sustainable transport $\cdot$ Ghana

\section{Introduction}

Reducing car-dependence is seen globally as crucial to reducing oil-dependence and traffic congestion while mitigating the associated negative impacts on the environment and public health. Consequently, within the transport sector, policy-strategies aimed at encouraging and increasing bicycle ridership, as a mainstream mode of transportation, have become common in many cities $[1,2]$.

Cycling, whether for utilitarian (commuting) or leisure purposes, provides many advantages over motorized modes of transport. As an active form of transport, moderate to regular intensity of cycling could be a strategy to reduce sedentary lifestyles and attain regular health-enhancing physical activity among a considerable part of the urban population [3-5]. Beside the health benefits, cycling is a cheap form of transport that offers flexible mobility, allows cyclists to avoid traffic jams, and provide support for multimodal transport connections $[6,7]$. The bicycle can travel distances long enough to efficiently cover many urban and suburban trips than walking [8] and in some cases, prove to be faster than other modes of transport [6]. Cycling trips are also environmentally sustainable than motorized trips as there are no direct emission of pollutants including green-house gases and noise [9]. Moreover, the infrastructural requirements of 
cycling are cheaper to build compared to motorized modes of transport [6].

Despite the many known benefits of utility cycling, bicycle mode share in most cities across the globe is still considerably low $[10,11]$. Within the context of developing countries, particularly in African cities, the low adoption rate has been attributed to the negative image of cycling in the population, which many perceive as inferior alternative to motorized transport; the lack of infrastructure for cycling; and the general failure of transport policy to incorporate cycling into the urban transport mix $[12,13]$.

Besides the negative perceptions of cycling among the population and the general lack of recognition of cycling as a mainstream transport mode, academic research on cycling and cycling behaviour in the African context has rather been limited. By far, the growing literature on cycling behaviour, that has contributed to our understanding of the myriad of factors influencing utility cycling, have been conducted within the context of Western European and American cities [1, 2, 14-16]. On the contrary, only a handful of research on utility cycling have so far emerged from the context of African cities [12, 13, 17-20]. Even so, with the exception of research by Nkurunziza and colleagues [20] in Dar-esSalaam, Tanzania and Acheampong [19] in Ghana, which provided some insights into the behavioural influences of urban cycling, the remaining studies focused mainly on the role (existing or potential) of cycling as a supplementary mode of transport.

Previous research has shown that bicycle ridership is influenced by the interplay of several factors. Consequently, some studies have adopted socio-ecological models, which capture the interaction between social, physical and policy environment factors and characteristics of individuals as determinants of cycling behaviour [21-26]. Other studies of the behavioural influences of cycling have drawn on the theory of planned behaviour (TPB) - a social cognitive framework from the psychology literature to understand how attitude, perceived behavioural control (PBC) and subjective norms (SNs) influence cycling behaviour [14, 27, 28].

The aim of this study is to explore the determinants of intended adoption of cycling as work travel mode among adult population in Kumasi, a medium size metropolis in Ghana, West Africa. Given that cycling is considered a behaviour under volitional control and that the current study focuses on intended adoption, TPB is deployed to understand the fundamental cognitive influences of cycling intentions by examining the population's attitudes, PBC (i.e. perception of how easy/difficult it would be to cycle) and SN (i.e. perception of general social pressure or (dis)approval by significant others to cycle). In addition to these sociopsychological constructs, the influence of factors, including gender, age, income, perceptions of the environment, bicycle ownership and use, and home-work distance on intended adoption of cycling as work travel mode in the metropolis are examined. In doing so, the current study contributes to the rather limited empirical enquiry on cycling behaviour within the context of African cities and hopes to provide the basis for cycling promotion interventions aimed at encouraging more people to cycle to work in the metropolis.

In the section that follows, TPB is discussed to provide the theoretical framework to model cycling intentions. This is followed by a discussion of the research design in section three. Section four presents the results of a structural equation model (SEM) of cycling intentions based on the TPB constructs, individual's socio-economic characteristics and perceptions of their environment. The final section summarises the key findings of the study and their policy implications.

\section{Understanding Cycling Behaviour: A Conceptual Framework}

As a mode of transport and a form of physical activity, a range of factors interplay to motivate, support or inhibit peoples' decision to adopt cycling. The literature points to four broad classes of determinants of cycling behaviour namely; psychological/cognitive factors, individual sociodemographic factors, physical (built) environment factors and natural environmental factors.

Most fundamental are the cognitive factors which comprise an individual's beliefs, attitude toward the behaviour, and perceptions with respect to a particular behaviour or choice alternatives. Within the psychology literature, one social cognitive model that has been applied extensively to understand the underlying motivations of different types of human behaviour under volitional control, including the decision to adopt active forms of transport such as walking and cycling, is the TPB [29, 30]. TPB posits that behavioural intentions are a function of three independent social cognitive constructs namely; attitude toward the behaviour, PBC and SN.

The TPB constructs are fundamentally determined by an individual's beliefs [31]. As Sutton et al. [31] explain, behavioural beliefs are held to determine attitude towards the behaviour of interest; normative beliefs (i.e. beliefs about the views of significant others) are held to determine SN while salient control beliefs (i.e. beliefs about factors that may facilitate or impede performance of the behaviour) are assumed to determine perceived behavioral control. Behavioural intentions in turn, are proximally linked to the performance of the behaviour [29, 32].

Within the TPB framework, attitude refers to the expectation of all the outcomes of an activity or behaviour and the personal values of these outcomes [30, 31]. In relations to cycling, attitude reflect an individual's global positive or 
negative evaluation of the outcomes of adopting the bicycle as a mode of transportation. Attitude have both affective and instrumental components. Whereas affective attitude reflects a person's feelings or emotions about the attitude objectcycling in this context-such as fear, fun or hate, instrumental attitude refers to a more cognitive consideration of the extent to which performing the behaviour (i.e. cycling) would be beneficial or advantageous [33]. Thus, in general, the more favourable the attitude towards a behaviour, the stronger the individual's intention to perform it $[29,34]$.

PBC, refers to an individual's perception of the ease or difficulty of performing the behaviour of interest. PBC reflect past experiences as well as anticipated impediments and obstacles to performing a particular activity or behaviour as perceived by the individual. Applied to cycling, PBC would reflect the individual's perceived power of specific factors to facilitate or inhibit his/her ability to cycle. These factors could be internal also referred to as self-efficacy and external control factors. Perceived self-efficacy refers to an individual's judgments of how well she/he can execute courses of action required to deal with prospective situations [30].

$\mathrm{SN}$, the third predictor of intention and behaviour, refers to social norms held by society or a group of people which influence and regulate behaviour by functioning as informal social controls [35]. Often, people may adapt their behaviour in line with these norms in order to fit with a certain group. For example, if an individual perceive that significant others will endorse (or disapprove) of their decision to cycle, they are more (or less) likely to adopt cycling. In addition, parents may not allow their children to cycle out of safety concerns. Similarly, if cycling is generally perceived by a group of people as a mode of transport for the poor or rural folks, then the accompanying stigma could discourage people from using it. Thus, SN comprise the perception of general social pressure with respect to performing a particular behaviour, action or activity.

A number of factors may mediate the causal effects of the constructs of the TPB on behavioural intentions with respect to cycling. Cycling is influenced by built environment attributes and neighbourhood design factors such as the presence of bike-lane connectivity segregated from vehicular traffic $[1,4]$ the density and mix of land use activities and the degree of spatial separation (i.e. distance) between activities and facilities [6]. The spatial context of the cycling environment, from spaces available to interactions with other travellers, affect the embodied and emotional content of journeys by bike [36]. Moreover, natural environmental factors such as landscape, slope and weather (e.g. precipitation, temperature) could affect the adoption and frequency of use of the bicycle $[6,23,26]$. Finally, personal-level, socio-economic attributes including gender, age, income, vehicle ownership and household structure have also been reported in the literature to influence cycling either directly or as mediators of other factors $[8,19,37,38]$.

Several empirical studies have applied the constructs of the TPB to predict and explain cycling and cycling related behaviour such as helmet use mainly within the context of European and North American cities [27, 28, 39]. These studies have reported varying results with respect to the relative predictive power of each of the three constructs-attitude, SN and PBC on cycling behaviour. In general, they have found that the more favourable the attitude and SN with respect to a behaviour, and the greater the $\mathrm{PBC}$, the stronger an individual's intention to perform the behaviour under consideration.

\section{Methodology}

Empirical work for this study was conducted in the Kumasi metropolis, the second largest metropolis in Ghana, West Africa. With an estimated population of nearly two-million, the city is experiencing rapid physical expansion [40], increasing number of motorized transport and congestion [41]. According to the most recent comprehensive traffic survey information for the metropolis, commuting trips by motorized transport, either public or private, constitute over $80 \%$ of mode share: the use of the bicycle is however low, representing less than one percent of all trips in the city [42]. These attributes make the metropolis an interesting case to explore how people perceive the bicycle as a transport mode as well as their views of the factors that would motivate or inhibit their intention to cycle to work.

\section{Salient Belief Elicitation Survey}

In order to apply TPB to model cycling adoption intentions in the metropolis, two levels of survey were conducted. First, a salient belief elicitation survey was conducted to obtain the general beliefs of the population with respect to cycling to work. Salient beliefs or accessible beliefs are those that come to mind when respondents are asked open-ended questions with respect to the behaviour or action of interest [31, 43].

A convenience sample of 50 adult residents of the metropolis, with equal representation of male and female cyclists and non-cyclists, were recruited for the salient belief elicitation phase of the study. An open-ended questionnaire was used to assess each of the participants' expected behavioural outcomes, normative referents and control factors as they relate to cycling. For example, participates were asked the questions; "What would the advantages (or disadvantages) be of cycling to you?". In order to elicit normative referents, participants were asked the question "Are there any individuals or groups of people who would approve (or 
disapprove) of you cycling?". The question "What factors or circumstances would make it easy (or difficult) for you to cycle?" was posed to elicit participant's perceived control factors. The statement "cycle for at least $30 \mathrm{~min}$, three times per week for the next one year" was added to each question with the objective of making the participants view cycling as a long-term habitual activity. For each of the questions, respondents were asked to state as many factors as they possibly could, while the research team manually recorded their answers.

\section{Design of TPB-Based Questionnaire and the Actual Survey}

At the end of the elicitation studies, the factors identified by the respondents were manually extracted and grouped under each of the three belief constructs assessed. Under behavioural outcomes for example, the study participants outlined expectations of cycling as being 'fast', 'convenient' 'a source of exercise' and a 'cheap' mode of transport. Participants referred to 'family' 'friends', 'parents' 'colleagues' and 'social-stigma' under normative referents as significant others or factors that could influence their intention to cycle. Finally, among the control factors outlined by the respondents were 'fast traffic' 'careless drivers' 'too old to cycle' and lack of 'supportive environment' for cycling.

A TPB-based questionnaire was designed in which the above factors were used as evaluation items under each of the three constructs. The questionnaire consisted of closedended questions with responses measured on a 5-point Likert-scale. The questions formulated had both 'belief' items and their corresponding 'outcome evaluation' items. For example, attitudinal factors (both instrumental and affective) were assessed using the belief item: "Cycling to work, at least three times in a week, for the next one year would be a good source of exercise" with a 5-point scale of "Strongly Agree-Strongly disagree" and followed by the outcome evaluation item; "For me, exercising is..." "Very important-not important-at-all" to me. In assessing SN, the study participants responded to a number of statements an example of which was "Most people who are important to me would not approve of me cycling to work, at least three times in a week for the next one year"; followed by its corresponding evaluation item. Moreover, one of the items used to PBC was "For me to cycle to work, at least three times in a week for the next one year would be easy/difficult".

Cycling intention, the dependent variable in the study, was measured using two indicator statements: "I intend cycle to work, at least three times in a week for the next one year" and "I will consider cycling to work, at least three times in a week for the next one year".

In addition to these questions, the survey gathered information on the respondents' perception of their environment and background characteristics including age, gender, education, previous cycling experience and bicycle ownership.

A total of 500 adults constituted the sample for the actual survey. These were randomly recruited from four proxy communities in the metropolis, namely; Bantama, Ayigya, Kentinkrono, and Ahodwo. These communities were selected for the following reasons: Bantama is an indigenous inner-city mixed-income neighbourhood. Ayigya, is a lowincome neighbourhood located within the inner-suburban zone of the city. Whereas Ahodwo is considered one of the high-income neighbourhoods located in the metropolis' inner-suburban zone, Kentinkrono exhibits characteristics of mixed middle-income and high-income neighbourhood, located within the outer-suburban zone of the city. The physical location and socio-economic characteristics of the selected neighbourhoods allowed to capture data representative of the diversity of population in the metropolis.

For each of the proxy communities, a total of 125 questionnaires were administered to adults aged from 18 years who were at home as of the time of the survey and were willing to be interviewed. In order to have a good representation of the population, the surveys were conducted during the day and evening times on both weekdays and weekends. Respondents were either interviewed face-to-face by trained field assistants or could opt to self-complete the questionnaire in the presence of a field assistant provided they could read and write. Overall, about $20 \%$ of the questionnaires were self-completed.

\section{Results}

This section presents the results of the field data. It begins with a discussion of the background characteristics of the study participants. This is followed with the specification of the SEM of intended adoption of cycling and interpretation of the estimated model parameters.

\section{Respondents' Background Information}

A summary of the characteristics of the study participants including their age, gender, levels of educational attainment, bicycle ownership, cycling experience and mode of transport to work and home-work distance is presented in Table 1. The study participants were adults aged between 18 years and 65 years, with an average age of 33 years. Most of the respondents (98\%) commuted to work using motorized transport while only one percent currently biked to work.

Moreover, four categories of respondents, based on selfreported cycling experience and frequency of use were identified. The first group, representing $6 \%$ of the respondents reported cycling to work frequently while the second group, comprising one-fifth indicated they cycled occasionally to 
Table 1 Background characteristics of study participants $(\mathrm{N}=500)$

\begin{tabular}{|c|c|c|}
\hline & Variable & Value \\
\hline \multirow[t]{6}{*}{ 1. Socio-economic characteristic } & Gender (male:female) & $49 \%: 51 \%$ \\
\hline & Age & Average $=33(\mathrm{SD}=10.7)$ \\
\hline & Basic education & $23 \%$ \\
\hline & Secondary education & $42 \%$ \\
\hline & Tertiary education & $35 \%$ \\
\hline & Income & Average $=\mathrm{GHC} 873.76(\mathrm{SD}=\mathrm{GHC667.92})$ \\
\hline \multirow[t]{7}{*}{ 2. Work travel mode } & Home-work distance & Average $=3.03 \mathrm{~km}(\mathrm{SD}=2.09 \mathrm{~km})$ \\
\hline & Work travel mode-private car & $11 \%$ \\
\hline & Work travel mode-public transport (taxi) & $13 \%$ \\
\hline & Work travel mode-public transport (minibus) & $72 \%$ \\
\hline & Work travel mode-motor-cycle & $3 \%$ \\
\hline & Work travel mode-walking & $1 \%$ \\
\hline & Work travel mode-cycling & $1 \%$ \\
\hline \multirow[t]{5}{*}{ 3. Bike-ownership and usage } & Never cycled & $30 \%$ \\
\hline & Cycled in the past & $44 \%$ \\
\hline & Cycle occasionally (at least once a week) & $20 \%$ \\
\hline & Cycle frequently (at least three times a week) & $6 \%$ \\
\hline & Bike ownership (yes: no) & $15 \%: 75 \%$ \\
\hline
\end{tabular}

work. Whereas $44 \%$ of the respondents reported that they had cycled sometime in the past, the remaining 30\% indicated that they had never cycled in their lifetime. These constituted the third and fourth groups respectively. Thus, overall, about $70 \%$ of the respondents had experienced cycling. With regards to bicycle ownership, the results show that $15 \%$ of the respondents owned a bike.

\section{Modelling Cycling Intentions: Specification of an SEM}

In modelling intended adoption of cycling as work travel mode, an SEM analysis was performed using data from the $70 \%$ of the survey respondents $(\mathrm{N}=348)$ who cycled either in the past or were currently cycling to work. The remaining $30 \%$ of the respondents who had never cycled were excluded from the analysis.

SEM was the preferred technique over standard regression models because of the complexity involved in using multiple observed indicators of each of the TPB constructs to model intention. The technique allows complex phenomenon to be statistically modelled, tested and to examine the validity and reliability of the observed model parameter estimates [44]. The SEM analysis was performed in AMOS statistical package [45].

A two-stage approach was adopted in understanding the populations' intended adoption of cycling to work. Firstly, a measurement model was specified using confirmatory factor analysis (CFA). This was followed by the specification of the structural model. At each stage, the specified model, showing the hypothesized relationships among the
TPB constructs and their corresponding observed indicators, were assessed to ascertain the degree to which they fitted the data using a number of goodness-of-fit indices prescribed in SEM analysis.

\section{Specification of the Measurement Model: A Confirmatory Factor Analysis}

The measurement model consists of latent variables (i.e. unobserved constructs of the TPB) and their respective observed indicator variables. In order to obtain a composite variable for each belief item, the scores for each of the belief statements were multiplied by the score for their corresponding outcome evaluation items [27]. A descriptive analysis of the study participants' response to the questionnaire items is presented in Table 2 followed by the specification of the measurement model in Fig. 1.

As shown in the path diagram (Fig. 1), the CFA model depicts the three latent constructs (shown as circles) of the TPB-attitude, PBC and SN. For each of these latent factors, their observed indicator variables are shown in a rectangular box with an arrow pointing from the latent variable to their corresponding indicator variables. The three latent variables are assumed to affect each other, represented by double-pointed arrows that show feedback relationship between them.

The degree of fitness between the model and the observational data in the measurement model was assessed using prescribed model identification indices [46, 47]. The model identification indices (see Fig. 1) show that the CFA 
Table 2 Descriptive analysis of participants' evaluation of questionnaire items $(\mathrm{N}=348)$

\begin{tabular}{lll}
\hline Questionnaire items & Mean & SD \\
\hline Attitude & & \\
Cycling to work would be fun & 2.61 & 2.29 \\
Cycling to work would be fast & 2.02 & 1.24 \\
Cycling to work would be flexible & 2.48 & 1.92 \\
Cycling to work would be convenient & 2.19 & 1.12 \\
Cycling to work would be comfortable & 2.36 & 1.11 \\
Cycling to work would be safe & 2.05 & 1.07 \\
Cycling to work would be a source of exercise & 1.30 & 1.10 \\
Cycling to work would make me healthy & 1.16 & 0.49 \\
Perceived behavioural control & 2.11 & 0.97 \\
For me to cycle would be easy & 1.80 & 0.93 \\
I am confident I can cycle to work & 1.37 & 0.75 \\
If I wanted, I could cycle to work & & \\
Subjective norm & 3.93 & 3.28 \\
My close family (e.g. spouse, children) relations will not approve of me cycling to work \\
Most people who are important to me would not approve of me Cycling to work & 4.30 & 3.38 \\
Other people will think I am poor if I cycle to work & 5.04 & 3.18 \\
I consider cycling for transportation less prestigious & 3.56 & 2.89 \\
Perception of environment & 1.42 & 0.80 \\
There is heavy traffic on routes I usually use to get to work & 1.56 & 0.83 \\
Drivers drive too fast on routes I usually use to get to work & 1.28 & 0.66 \\
There are traffic lights on routes I usually use to get to work & 2.86 & 0.49 \\
There are dedicated lanes for cyclists along routes I usually get to work & 2.19 & 0.93 \\
Intention & 1.96 & 0.94 \\
I intend to cycle to work at least three times for the next one year & & \\
I will consider cycling to work at least three times for the next one year & & \\
\hline Cronbach's Alpha Atitus & & \\
\hline
\end{tabular}

Cronbach's Alpha Attitude $=0.70$, perceived behavioural control $=0.71$, Subjective norm $=0.73$, intention $=0.80$, perception of environment $=0.36$ was identified, which implies that the hypothesized direction of effects among the model variables is supported by the data.

Next, the parameters of the identified CFA were estimated using maximum likelihood (ML) method. ML estimation method was chosen over other estimation methods (i.e. asymptotically distribution-free, two-stage least squares, weighted least squares) because the data were normally distributed. The CFA shows a strong positive correlation between participants' attitude and $\mathrm{PBC}$, and negative correlations between attitude and $\mathrm{SN}$ and $\mathrm{PBC}$ and $\mathrm{SN}$. The contributions of the observed variables to each of the latent constructs they represent was assessed using squared multiple correlation (SMC) estimates of the CFA. SMC as a reliability measure is scaled from 0 to 1 , implying that the closer a value is to 1 , the better it is as a measure of the latent variable of interest. In the path diagram depicted in Fig. 1, the SMC values are shown on top of the rectangles containing the indicator variables. The results show that SMC ranges between 0.09 and 0.28 for attitudinal variables; $0.27-0.33$ for SN indicator variables; and 0.14-0.71 for PBC indicator variables. SMC values of all the indicators in the measurement model were statistically significant $(\mathrm{p}<0.01)$.

\section{Specification of the Structural Model}

The structural model, models the effects of the TPB constructs specified earlier in the CFA as well as participants' perception of their environment; personal characteristics including age, gender, education and income; and bicycle ownership and cycling frequency on intention to cycle to work.

The path diagram of the structural model is depicted in Fig. 2. Within the structural model, cycling intention was measured by two indicator variables: one which asked participants whether they "intend to cycle to work" and a varied version of the intention item which asked if they would "consider cycling to work". Each of the TPB constructs was hypothesized to affect intended adoption of cycling directly. In addition, participants' perception of their environment and their background attributes, each affected intended adoption of cycling directly. The structural model was first 


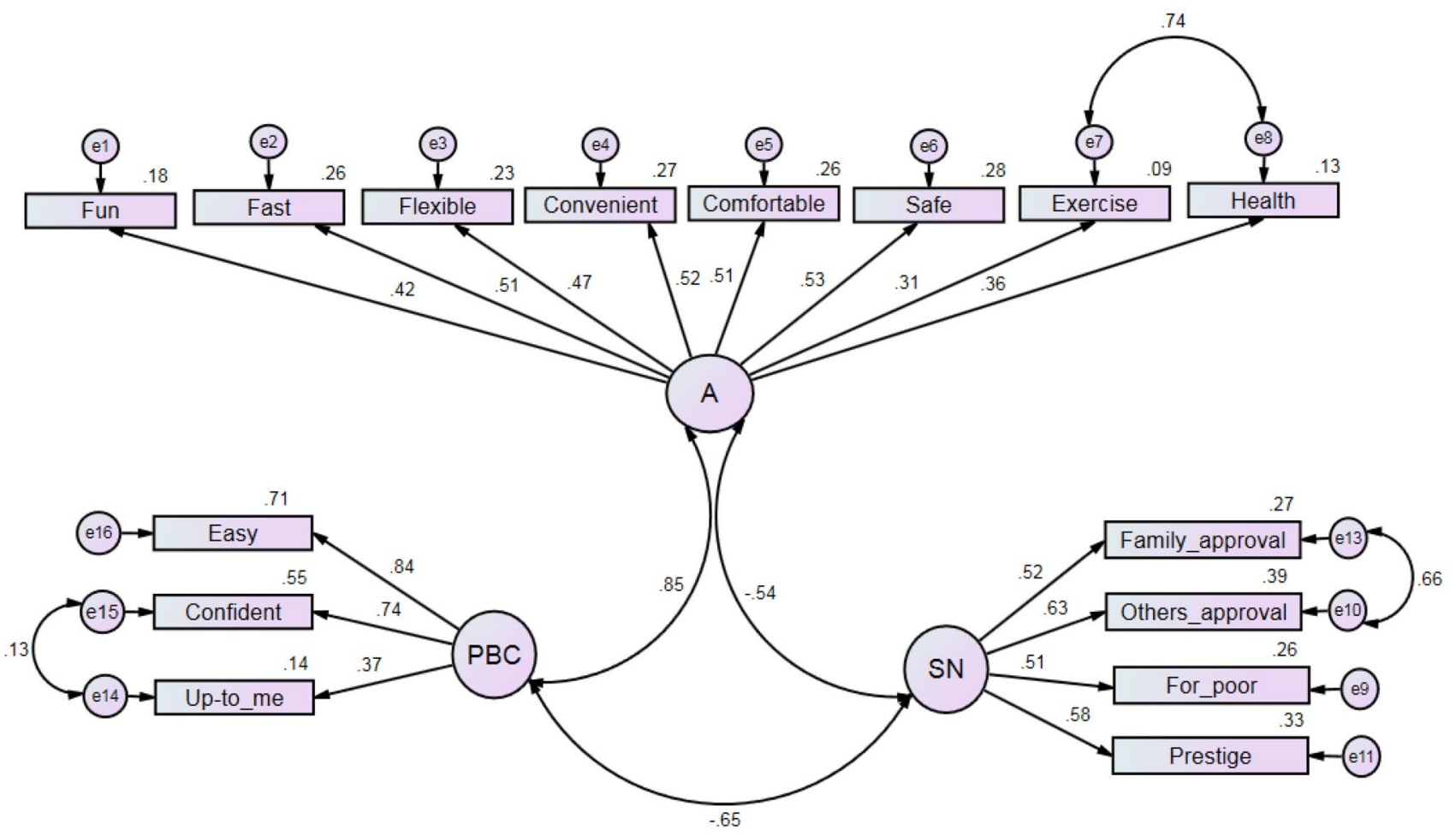

Fig. 1 Path diagram of an identified CFA showing indicator measures of attitude, PBC and SN. $A$ attitude, $S N$ subjective norm, $P B C$ perceived behavioural control, $e$ unobserved error term. Model identi- fication indices $\left(\chi^{2}=214.23, \mathrm{df}=84, \mathrm{p}<0.01\right.$; RMSEA $=0.067$; Nonnormed fit index $(\mathrm{NFI})=0.90$; Comparative fit index $(\mathrm{CFI})=0.91$. subjected to identification test using the same goodnessof-fit indices applied to the measurement model. The test showed that the structural model was identified, implying that the hypothesized direction of effects among the model variables were supported by the data.

The parameters of the structural model were estimated using ML method. This produced path co-efficient (or regression weights) shown on the arrows directed from the independent variables to the dependent variable (i.e. cycling adoption) as depicted in Fig. 2. The path co-efficient of the SEM is interpreted as regression co-efficient in standard multiple-regression models, which means that they control for correlations among multiple presumed causes [48]. Table 3 shows the estimated path co-efficient of the structural model. The correlation and covariance estimates of the model follows in Table 4.

The SEM analysis showed that among TPB variables, PBC with standardized path co-efficient of 0.95 had a large direct effect on participants' intention to adopt cycling as work travel mode. This implies that for every unit increase in participants' perceived control, intended adoption of cycling to work increases by 0.95 . The fact that the majority of the respondents (i.e. 70\%) had either previously cycled or were currently cycling could explain their stronger perceived control with respect to cycling. Moreover, correlation and covariance estimates (see Table 4) showed a strong positive association between attitude and PBC (correlation coefficient $=0.84, \mathrm{p}<0.01$ ). Thus, positive expectations of the outcomes of cycling was associated with stronger belief and confidence in being able to cycle.

On the contrary, attitude and SN as TPB constructs did not have statistically significant effect on intended adoption of cycling to work. Notwithstanding, results of the correlation estimates show a negative association between $\mathrm{SN}$ and attitude (correlation co-efficient $=0.58, \mathrm{p}<0.01$ ) and $\mathrm{PBC}$ and $\mathrm{SN}$ (correlation co-efficient $=0.70, \mathrm{p}<0.01$ ). Although these do not prove causation, it is reasonable to expect negative perceptions of significant others and the wider society towards cycling to negatively affect attitudes, personal confidence and belief of control with respect to cycling.

Beside the TPB variables, variables measuring participants' perception of their environment influenced positively intended adoption of cycling to work. The associated path co-efficient of 0.26 imply that as participants' perception of their environment as being supportive of cycling increases by one unit, intended adoption of cycling to work increases by 0.26 . Examining the contributions of the individual variables measuring perception of the environment show that perception of traffic signals, heavy traffic flow and fast moving traffic, contributed positively to this construct. Traffic 


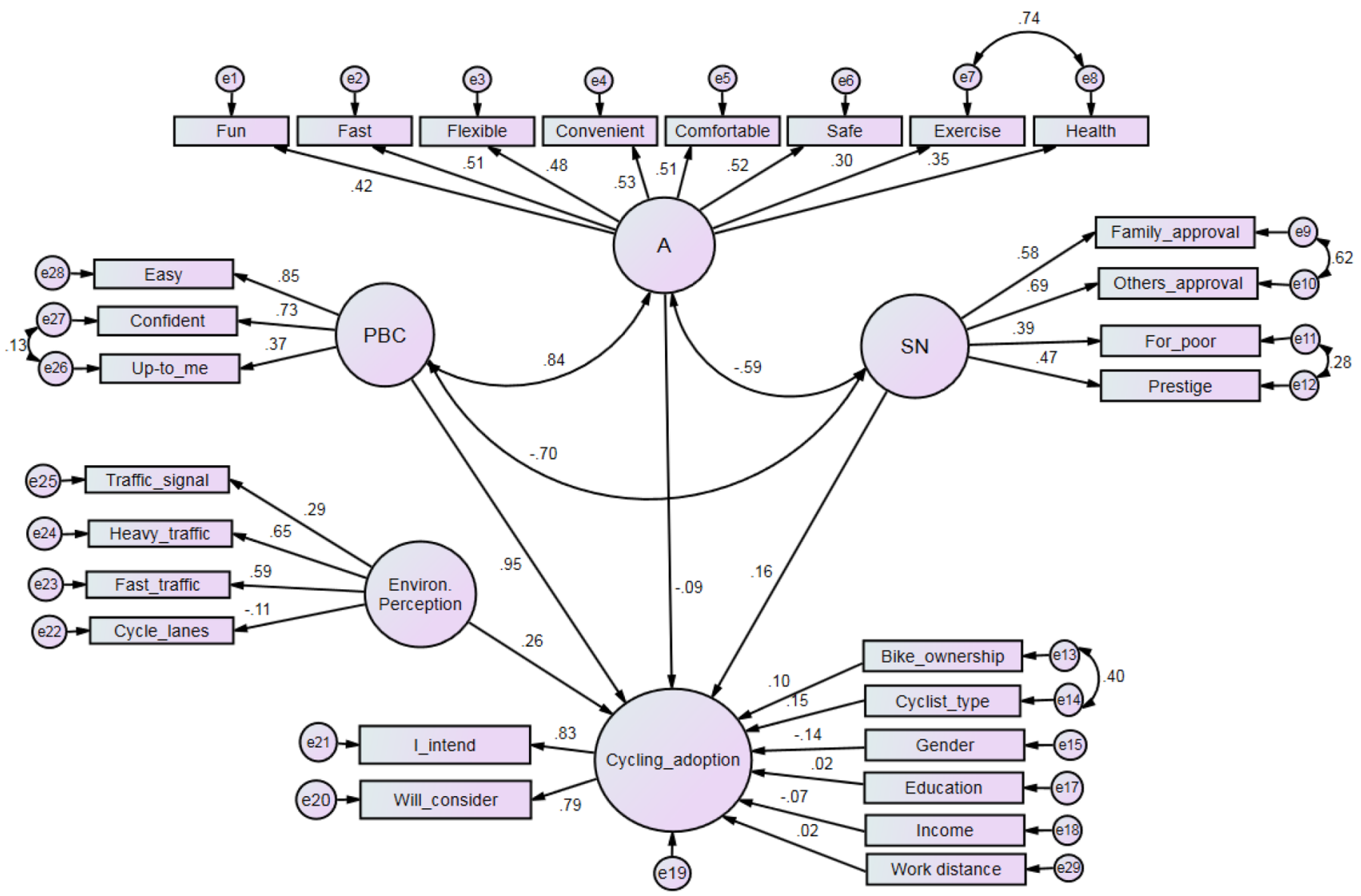

Fig. 2 Path diagram of an identified SEM, showing the effects of latent constructs and observed variables on cycling adoption intention. $A$ attitude, $S N$ subjective norm, $P B C$ perceived behavioural

signals imply that traffic flow is regulated at intersections which could enhance safety as perceived by cyclists and would-be cyclists. Heavy traffic indicates slow moving traffic and congestion, which is a common phenomenon during peak-hours in the case study metropolis. In congested streets, cycling could prove to be faster than motorized transport. The availability of cycling lanes contributed negatively to perception of the environment although the result was not statistically significant. Despite this, its negative contribution to the physical environmental perception is supported by the lack of dedicated cycling lanes that could easily be observed in the study area.

The effect of bicycle ownership on intended adoption of cycling as work transport mode was also significant. The results show bicycle ownership increases intended adoption by 0.10 . Similarly, 'cyclist-type', which in the model reflects bicycle usage and frequency, affected intended adoption of the bike as work travel mode positively. The analysis showed that as cycling usage and frequency increases by one unit from 'previous-cyclists' towards 'frequent-cyclists', intended adoption of cycling as work travel mode increases by 0.15 . Indeed, the correlation between the unobserved error terms control, $e$ unobserved error term. Model identification indexes $\left(\chi^{2}=664.36, \mathrm{df}=287, \mathrm{p}<0.01 ; \mathrm{RMSEA}=0.062 ;\right.$ non-normed fit index $(\mathrm{NFI})=0.74$; comparative fit index $(\mathrm{CFI})=0.83$.

of 'cyclist-type' and bicycle-ownership revealed a moderate association between the two variables (correlation coefficient $=0.4, \mathrm{p}<0.01$ ).

Moreover, the gender of the study participants influenced intended adoption of cycling as work travel mode. The model estimates show that, as gender changes from male to female, intended adoption of cycling decreases by -0.136 . In other words, being female decreased the likelihood of intended cycling adoption. Participants' levels of educational attainment, income as well as home-work commuting distance, however, did not yield significant effects on intended adoption of cycling.

The model's SMC, equivalent to the $\mathrm{R}^{2}$ in standard regression analysis was 0.73 , indicating that about $73 \%$ of the variance in intended adoption of cycling as work travel mode is explained by the variables captured in the SEM.

\section{Discussion and Conclusion}

This study has modelled the behavioural influences of individuals' intended adoption of cycling for work purposes in 
Table 3 Maximum likelihood parameter estimates for an identified SEM of cycling adoption intentions

\begin{tabular}{|c|c|c|c|c|c|c|c|}
\hline & & & Unstandardized & S.E. & Standardized & C.R. & $\mathrm{p}$ \\
\hline Cycling adoption & $\leftarrow$ & PBC & 0.842 & 0.215 & 0.951 & 3.921 & $* * *$ \\
\hline Cycling adoption & $\leftarrow$ & $\mathrm{SN}$ & 0.095 & 0.075 & 0.162 & 1.255 & 0.209 \\
\hline Cycling adoption & $\leftarrow$ & $\mathrm{A}$ & -0.113 & 0.229 & -0.092 & -0.494 & 0.621 \\
\hline Cycling adoption & $\leftarrow$ & Environ perception & 0.383 & 0.103 & 0.258 & 3.726 & $* * *$ \\
\hline Cycling adoption & $\leftarrow$ & Bike ownership & 0.212 & 0.099 & 0.104 & 2.146 & $0.032 *$ \\
\hline Cycling adoption & $\leftarrow$ & Cyclists-type & 0.233 & 0.073 & 0.155 & 3.176 & $0.001 *$ \\
\hline Cycling adoption & $\leftarrow$ & Home-work distance & 0.008 & 0.018 & 0.021 & 0.411 & 0.681 \\
\hline Cycling adoption & $\leftarrow$ & Gender & -0.204 & 0.067 & -0.136 & -3.036 & $0.002 *$ \\
\hline Cycling adoption & $\leftarrow$ & Education & 0.023 & 0.044 & 0.023 & 0.529 & 0.597 \\
\hline Cycling adoption & $\leftarrow$ & Income & 0.001 & 0.001 & -0.064 & -1.452 & 0.147 \\
\hline Health & $\leftarrow$ & A & 0.293 & 0.056 & 0.352 & 5.22 & $* * *$ \\
\hline Exercise & $\leftarrow$ & A & 0.556 & 0.122 & 0.301 & 4.571 & $* * *$ \\
\hline Comfortable & $\leftarrow$ & A & 0.957 & 0.139 & 0.511 & 6.87 & $* * *$ \\
\hline Fun & $\leftarrow$ & A & 1.632 & 0.271 & 0.423 & 6.018 & $* * *$ \\
\hline Fast & $\leftarrow$ & A & 1.062 & 0.155 & 0.51 & 6.858 & $* * *$ \\
\hline Flexible & $\leftarrow$ & A & 1.56 & 0.237 & 0.48 & 6.591 & $* * *$ \\
\hline Convenient & $\leftarrow$ & A & 1 & & 0.528 & & \\
\hline Safe & $\leftarrow$ & A & 0.93 & 0.134 & 0.517 & 6.924 & $* * *$ \\
\hline Others approval & $\leftarrow$ & SN & 1.868 & 0.375 & 0.688 & 4.979 & $* * *$ \\
\hline Prestige & $\leftarrow$ & $\mathrm{SN}$ & 1.088 & 0.191 & 0.468 & 5.68 & $* * *$ \\
\hline Poor & $\leftarrow$ & $\mathrm{SN}$ & 1 & & 0.391 & & \\
\hline Family approval & $\leftarrow$ & SN & 1.52 & 0.324 & 0.576 & 4.694 & $* * *$ \\
\hline Easy & $\leftarrow$ & PBC & 1 & & 0.849 & & \\
\hline Up-to-me & $\leftarrow$ & $\mathrm{PBC}$ & 0.337 & 0.052 & 0.372 & 6.524 & $* * *$ \\
\hline Confident & $\leftarrow$ & PBC & 0.834 & 0.059 & 0.734 & 14.19 & $* * *$ \\
\hline Fast traffic & $\leftarrow$ & Environ perception & 1 & & 0.589 & & \\
\hline Heavy traffic volume & $\leftarrow$ & Environ perception & 1.049 & 0.248 & 0.644 & 4.231 & $* * *$ \\
\hline Bike lanes & $\leftarrow$ & Environ perception & -0.108 & 0.071 & -0.108 & -1.518 & 0.129 \\
\hline Traffic signals & $\leftarrow$ & Environ perception & 0.389 & 0.108 & 0.287 & 3.612 & $* * *$ \\
\hline I Intend to cycle & $\leftarrow$ & Cycling adoption & 1.025 & 0.074 & 0.825 & 13.807 & $* * *$ \\
\hline Will consider cycling & $\leftarrow$ & Cycling adoption & 1 & & 0.795 & & \\
\hline
\end{tabular}

$P B C$ perceived behavioural control, $A$ attitude, $S N$ subjective norm, $S E$ standard error, $C R$ critical value $* * *$ Significant at $\mathrm{p}<0.01, \mathrm{R}^{2}=0.73$

Table 4 Maximum Likelihood estimates of covariance and correlations for an identified SEM of cycling adoption intentions

\begin{tabular}{|c|c|c|c|c|c|c|c|}
\hline & & & Covariance & S.E. & Correlations & C.R. & $\mathrm{p}$ \\
\hline A & $\leftrightarrow$ & SN & -0.430 & 0.106 & -0.585 & C.R & $* * *$ \\
\hline A & $\leftrightarrow$ & PBC & 0.409 & 0.057 & 0.843 & -4.076 & $* * *$ \\
\hline SN & $\leftrightarrow$ & PBC & -0.717 & 0.149 & -0.704 & 7.215 & $* * *$ \\
\hline e13 & $\leftrightarrow$ & e14 & 0.069 & 0.010 & 0.399 & -4.798 & $* * *$ \\
\hline e7 & $\leftrightarrow$ & e8 & 0.355 & 0.033 & 0.739 & 6.904 & $* * *$ \\
\hline e26 & $\leftrightarrow$ & $\mathrm{e} 27$ & 0.055 & 0.027 & 0.126 & 10.647 & 0.041 \\
\hline e10 & $\leftrightarrow$ & e9 & 4.054 & 0.823 & 0.619 & 2.041 & $* * *$ \\
\hline e12 & $\leftrightarrow$ & e11 & 2.075 & 0.495 & 0.278 & 4.923 & $* * *$ \\
\hline
\end{tabular}

$P B C$ perceived behavioural control, $A$ attitude, $S N$ subjective norm, $S E$ standard error, C.R. critical ratio, $e$ unobserved error term

*** Significant at $\mathrm{p}<0.01$ 
the Kumasi metropolis in Ghana, West Africa. TPB variables-attitude, SN and perceived control were deployed to capture the fundamental psychological influences of cycling adoption within the population. The influence of variables measuring the participants' perception of their physical environment as well as their personal characteristics, cycling history and bicycle ownership were also examined.

Overall, the study has shown that among TPB variables, $\mathrm{PBC}$ had the strongest direct and positive effect on participants' intention to cycle to work. Findings of research by $[27,35]$ on active transport (i.e. walking and cycling) corroborate the strong influence of $\mathrm{PBC}$ on behavioural intentions reported by this research. The finding suggests that participants' belief of cycling as an easy activity over which they have personal control to perform as well as confidence in their ability to ride the bicycle, have strong effect on cycling intentions. In addition, $\mathrm{PBC}$ reflect past experiences and perception of barriers, meaning that its strong predictive effect on cycling intention reported in this study could be attributed to the fact that the majority of the population had either cycled previously or were currently cycling to work.

Despite attitude and SN as TPB variables not showing direct significant influence on intended adoption of cycling to work, the study found that between SN and attitude and $\mathrm{PBC}$ and SN were negatively correlated. Although the direction of causation is not established by the test of association, it could reasonably be inferred that participants' belief of the prestige of cycling relative to other modes of transport, and approval of society and significant others of cycling could impact perception of control and confidence as well as attitude with respect to cycling.

Furthermore, participants' perception of attributes of their environment including traffic lights, heavy traffic and congested streets determined intended adoption of cycling. Previous research show that traffic signals and traffic calming measures have positive influences on cycling behaviour [49]. Similarly, in contexts where traffic congestion is a major problem for daily commute, the bicycle provides a much faster alternative [6].

Moreover, consistent with previous studies of cycling behaviour $[19,38,50]$, this research has showed that being female decreased the likelihood of intended cycling adoption. Expectedly, bicycle ownership and frequency of use shown positive influences on intention to adopt cycling as work travel mode.

The findings of the current study have a number of implications for cycling promotion interventions. The strong personal control in the population with respect to cycling could provide a useful starting point for undertaking cycling promotion interventions aimed at getting more people in the city to opt for the bicycle as work travel mode. Given the positive association between perceived control and attitudes, as well as the negative associations between $\mathrm{SN}$ and attitudes and
SN and perceived control demonstrated in this study, cycling promotion interventions could focus on creating awareness among the general populace of the benefits they could derive from commuting by the bicycle. Dealing with cycling's public image as a less prestigious mode of transport while providing dedicated cycling lanes and pursuing policy measures aimed at increasing bicycle ownership particularly at the work-place could get more people to adopt cycling.

Finally, the current study could be taken forward in a number of ways. In addition to the variables included in the study, the effect of natural environmental factors such as weather and relief as well as built-environment factors such as land-use mix, density and the distribution of work and non-work activities could also be explored. Future research could also focus on cycle use in non-adult populations such as teenagers, and explore their perceptions and attitude towards cycling to school for example. This could provide the basis for the design and implementation of cycling promotion interventions targeting this category of potential cyclists.

Open Access This article is distributed under the terms of the Creative Commons Attribution 4.0 International License (http://creativecommons.org/licenses/by/4.0/), which permits unrestricted use, distribution, and reproduction in any medium, provided you give appropriate credit to the original author(s) and the source, provide a link to the Creative Commons license, and indicate if changes were made.

\section{References}

1. Larsen J, El-Geneidy A (2011) A travel behavior analysis of urban cycling facilities in Montréal, Canada. Transp Res Part D Transp Environ 16(2):172-177

2. Pucher J, Buehler R (2012) City cycling. MIT Press

3. Haskell WL (2004) General dose response issues concerning physical activity and health. Health Enhanc Phys Act 6:149-168

4. Titze $\mathrm{S}$ et al (2008) Association of built-environment, social-environment and personal factors with bicycling as a mode of transportation among Austrian city dwellers. Prev Med 47(3):252-259

5. Van Dyck D et al (2013) Physical environmental attributes and active transportation in belgium: what about adults and adolescents living in the same neighborhoods? Am J Health Promot 27(5):330-338

6. Heinen E, van Wee B, Maat K (2010) Commuting by bicycle: an overview of the literature. Transp Rev 30(1):59-96

7. Shaheen S, Guzman S, Zhang H (2010) Bikesharing in Europe, the Americas, and Asia: past, present, and future. Transp Res Rec 2143:159-167

8. Moudon AV et al (2005) Cycling and the built environment, a US perspective. Transp Res Part D Transp Environ 10(3):245-261

9. Handy S, Van Wee B, Kroesen M (2014) Promoting cycling for transport: research needs and challenges. Transp Rev 34(1):4-24

10. Gatersleben B, Appleton KM (2007) Contemplating cycling to work: attitudes and perceptions in different stages of change. Transp Res Part A Policy Pract 41(4):302-312

11. Heesch KC, Giles-Corti B, Turrell G (2014) Cycling for transport and recreation: associations with socio-economic position, environmental perceptions, and psychological disposition. Prev Med 63:29-35 
12. Brussel M, Zuidgeest M (2012) Cycling in developing countries: context, challenges and policy relevant research, Chap. 8. In: Parkin J (ed) Cycling and sustainability. Emerald Group Publishing Limited, Bingley, pp 181-216

13. Nkurunziza A, Zuidgeest M, Van Maarseveen M (2012) Identifying potential cycling market segments in Dar-es-Salaam, Tanzania. Habitat Int 36(1):78-84

14. de Bruijn G-J et al (2009) Adult active transportation: adding habit strength to the theory of planned behavior. Am J Prev Med 36(3):189-194

15. Dill J, McNeil N (2013) Four types of cyclists? Examination of typology for better understanding of bicycling behavior and potential. Transp Res Rec 2387:129-138

16. Kaplan S, Prato CG (2016) "Them or Us": Perceptions, cognitions, emotions, and overt behavior associated with cyclists and motorists sharing the road. Int J Sustain Transp 10(3):193-200

17. Bechstein E (2010) Cycling as a supplementary mode to public transport: a case study of low income commuters in South Africa. In: 29th southern african transport conference

18. Sambali G, Zuidgeest M, De Langen M (1999) Determinants of cycling in medium and large cities in sub-Saharan Africa. In: World transport research: selected proceedings of the 8th world conference of transport research

19. Acheampong RA (2016) Cycling for sustainable transportation in urban Ghana: exploring attitudes and perceptions among adults with different cycling experience. J Sustain Dev 9(1):110

20. Nkurunziza A et al (2012) Examining the potential for modal change: motivators and barriers for bicycle commuting in Dares-Salaam. Transp policy 24:249-259

21. Robertson-Wilson JE, Leatherdale ST, Wong SL (2008) Socialecological correlates of active commuting to school among high school students. J Adolesc Health 42(5):486-495

22. Handy SL, Xing Y (2011) Factors correlated with bicycle commuting: a study in six small US cities. Int J Sustain Transp 5(2):91-110

23. Mitra R, Faulkner G (2012) There's no such thing as bad weather, just the wrong clothing: climate, weather and active school transportation in Toronto, Canada. Can J Public Health 103(9):S35-S40

24. Piatkowski DP, Marshall WE (2015) Not all prospective bicyclists are created equal: the role of attitudes, socio-demographics, and the built environment in bicycle commuting. Travel Behav Soc 2(3):166-173

25. Willis DP, Manaugh K, El-Geneidy A (2015) Cycling under influence: summarizing the influence of perceptions, attitudes, habits, and social environments on cycling for transportation. Int J Sustain Transp 9(8):565-579

26. Saneinejad S, Roorda MJ, Kennedy C (2012) Modelling the impact of weather conditions on active transportation travel behaviour. Transp Res Part D Transp Environ 17(2):129-137

27. Bamberg S, Ajzen I, Schmidt P(2003) Choice of travel mode in the theory of planned behavior: the roles of past behavior, habit, and reasoned action. Basic Appl Soc Psychol 25(3):175-187

28. Lajunen T, Räsänen M (2004) Can social psychological models be used to promote bicycle helmet use among teenagers? A comparison of the health belief model, theory of planned behavior and the locus of control. J Safety Res 35(1):115-123

29. Ajzen I (1985) From intentions to actions: a theory of planned behavior, in action control. Springer, Berlin, pp 11-39

30. Ajzen I (1991) The theory of planned behavior. Organ Behav Human Decis process 50:179-211
31. Sutton S et al (2003) Eliciting salient beliefs in research on the theory of planned behaviour: the effect of question wording. Curr Psychol 22(3):234-251

32. Andrykowski MA et al (2006) Application of the theory of planned behavior to understand intentions to engage in physical and psychosocial health behaviors after cancer diagnosis. PsychoOncology 15(9):759-771

33. French DP et al (2005) The importance of affective beliefs and attitudes in the theory of planned behavior: predicting intention to increase physical activity1. J Appl Soc Psychol 35(9):1824-1848

34. Armitage CJ, Conner M (2001) Efficacy of the theory of planned behaviour: a meta-analytic review. Br J Soc Psychol 40(4):471-499

35. Eves F, Hoppéa R, McLaren L (2003) Prediction of specific types of physical activity using the theory of planned behavior. J Appl Biobehav Res 8(2):77-95

36. Bonham J, Koth B (2010) Universities and the cycling culture. Transp Res Part D Trans Environ 15(2):94-102

37. Bull F et al (2000) Physical activity levels of Western Australian adults 1999. Health Department of Western Australia and Sport and Recreation Way2Go, Western Australian Government, Perth

38. Emond C, Tang W, Handy S (2009) Explaining gender difference in bicycling behavior. Transp Res Rec 2125:16-25

39. Quine L, Rutter DR, Arnold L (1998) Predicting and understanding safety helmet use among schoolboy cyclists: a comparison of the theory of planned behaviour and the health belief model. Psychol Health 13(2):251-269

40. Acheampong RA, Agyemang FS, Abdul-Fatawu M (2017) Quantifying the spatio-temporal patterns of settlement growth in a metropolitan region of Ghana. GeoJournal 82(4):823-840

41. Adarkwa Kwasi Kwafo P.-B.M. (2011) Rising vehicle ownership, roadway challenges and traffic congestion in Kumasi In: Kwafo AK (ed) Future of the tree, towards growth and development of Kumasi.KNUST University Press, Kumasi

42. Department of Urban Roads (2004) Consultancy services for urban transport planning and traffic management studies for Kumasi and Tamale. Interim report vol 2

43. Sun G et al (2015) Understanding walking behavior among university students using theory of planned behavior. Int J Environ Res Public Health 12(11):13794-13806

44. Lomax RG, Schumacker RE (2012) A beginner's guide to structural equation modeling. Routledge Academic, New York

45. Arbuckle J, Wothke W (2006) AMOS user's guide 7.0. AMOS Development Corporation, Spring House

46. Hooper D, Coughlan J, Mullen M (2008) Evaluating model fit: a synthesis of the structural equation modelling literature. In: 7th European conference on research methodology for business and management studies

47. Schreiber JB et al (2006) Reporting structural equation modeling and confirmatory factor analysis results: a review. J Educ Res 99(6):323-338

48. Kline RB (2015) Principles and practice of structural equation modeling. Guilford publications, New York

49. Pucher J, Buehler R, Seinen M (2011) Bicycling renaissance in North America? An update and re-appraisal of cycling trends and policies. Transp Res Part A Policy Pract 45(6):451-475

50. Akar G, Fischer N, Namgung M (2013) Bicycling choice and gender case study: The Ohio State University. Int J Sustain Transp 7(5):347-365 